\title{
A FAMÍlIA BOMBACACEAE KUNTH NO ESTADO DE PERNAMBUCO, BRASIL ${ }^{1}$
}

\author{
Ana Luiza Du Bocage ${ }^{2}$ \\ Margareth Ferreira de Sales ${ }^{3}$
}

Recebido em 18/04/2000. Aceito em 13/08/2001.

RESUMO - (A família Bombacaceae Kunth no estado de Pernambuco - Brasil). O presente trabalho consiste de um estudo taxonômico sobre a família Bombacaceae no Estado de Pernambuco, Brasil. Constatou-se a ocorrência de sete espécies distribuídas em seis gêneros: Bombacopsis retusa (Mart. \& Zucc.) A. Robyns, Ceiba glaziovii (Kuntze) K. Schum., Eriotheca crenulaticalyx A. Robyns, Pachira aquatica Aubl., Pseudobombax marginatum (A. St.-Hil.) A. Robyns, Pseudobombax simplicifolium A. Robyns e Quararibea turbinata (Sw.) Poir. Chave para identificação das espécies, descrições, material examinado, ilustrações e comentários sobre distribuição geográfica e habitat são apresentados. Bombacopsis retusa e Pseudobombax marginatum são referidas pela primeira vez para Pernambuco.

Palavras-chave - Taxonomia, Levantamento, Bombacaceae, Pernambuco, Brasil

ABSTRACT - (The family Bombacaceae Kunth in the state of Pernambuco - Brazil).The present work is a taxonomic study on the family Bombacaceae in the State of Pernambuco, Brazil. Seven species were found, distributed in six genera: Bombacopsis retusa (Mart. \& Zucc.) A. Robyns, Ceiba glaziovii (Kuntze) K. Schum., Pachira aquatica Aubl., Pseudobombax marginatum (A. St.-Hil.) A. Robyns, Pseudobombax simplicifolium A. Robyns and Quararibea turbinata (Sw.) Poir. Species, Key descriptions, examined material, illustrations and comments on the geographic distribution and habitat are presented. Bombacopsis retusa and Pseudobombax marginatum are recorded for the first time in the State of Pernambuco.

Keys words - Taxonomy, Survey, Bombacaceae, Pernambuco, Brazil

\section{Introdução}

A família Bombacaceae Kunth está representada por cerca de 30 gêneros e, aproximadamente, 200 espécies de distribuição pantropical, predominantemente nas Américas, com alguns gêneros na África e Ásia (Cronquist 1981). No Brasil, ocorrem cerca de 18 gêneros e 100 espé- cies amplamente distribuídas, habitando diferentes formações vegetais (Barroso et al. 1978).

Os trabalhos clássicos sobre Bombacaceae foram elaborados por De Candolle (1824), Bentham (1862 a, b) e Schumann (1886, 1895). Novas propostas de classificação e revisões a nível genérico, foram publicadas por Bakhuizen (1924), Robyns (1963b), Hutchinson (1967)

\footnotetext{
Parte da Dissertação de Mestrado da primeira autora desenvolvida na Universidade Federal Rural de Pernambuco UFRPE.

2 Seção de Botânica e Ecologia - Empresa Pernambucana de Pesquisa Agropecuária - IPA. Av. Gal. San Martin, 11371, Bongi, Recife - PE, Brasil. e-mail: dubocage@terra.com.br

Departamento de Biologia - Universidade Federal Rural de Pernambuco. Av. Dom Manuel de medeiros s/n, Dois Irmãos, Recife - PE, Brasil.
} 
Janeiro (Santos 1966), de Santa Catarina (Santos 1967), das restingas do sudeste brasileiro (Santos 1969), Serra do Cipó, Minas Gerais (Esteves 1992), Ilha do Cardoso, São Paulo (Esteves 1996) e da Reserva Ducke, Amazônia Central (Ribeiro \& Esteves 1999).

Portanto, este trabalho tem como objetivo o estudo taxonômico Bombacaceae em Pernambuco, procurando fornecer dados que contribuam para o entendimento dos gêneros e espécies além de atualizar suas distribuições geográficas e evidenciar características morfológicas importantes para o reconhecimento das espécies neste Estado.

\section{Material e métodos}

Para a análise de plantas vivas e obtenção de parte do material herborizado, foram procedidas coletas em cerca de 41 municípios do estado de Pernambuco, no período de março de 1991 a julho de 1993. As observações sobre os indivíduos no campo foram essenciais para o reconhecimento das espécies verificando-se dentro das características morfológicas vegetativas e/ou florais, as mais relevantes para a sua identificação. Exsicatas e material tipo foram solicitados, por empréstimo, a diversos herbários brasileiros ( abreviaturas segundo Holmgren et al. 1990; Barbosa \& Barbosa 1996): ALCB, EAC, HRB, HST, ICN, IPA, MG, PEUFR, RB, SP, SPF, UB, UEC, UFP.

As identificações das espécies foram procedidas através da comparação com diagnoses, material tipo e fotografias de tipos, quando possível. A descrição da família e dos gêneros baseou-se, principalmente, na bibliografia consultada, enquanto as descrições das espécies foram baseadas no material coletado em Pernambuco. Na citação do material examinado a condição fenológica está expressa pelas abreviaturas: $f=$ folhas, $f l=$ flores e fr= frutos. Os dados de floração e frutificação são para Pernambuco. O material coletado encontra-se incorporado ao acervo do herbário IPA.

\section{Resultados e discussão}

Bombacaceae Kunth, Nov. Gen. Sp. Plant. 5: 294. 1822.

Árvores ou arbustos inermes ou aculeados, muitas vezes com caule intumescido. Folhas com estípulas geralmente caducas, pecioladas, alternas, simples ou compostas, digitadas com folíolos sésseis a peciolulados, articulados ou inarticulados. Inflorescências axilares ou terminais, em cimas, fascículos ou díades e flores isoladas; flores perfeitas, actinomorfas ou zigomorfas, pediceladas com bractéolas caducas ou persistentes; cálice geralmente campanulado, ápice truncado, sinuoso, crenulado ou irregularmente lobado; corola geralmente com cinco pétalas livres entre si, adnatas a base do tubo estaminal, brancas, cremes, alaranjadas, vermelhas ou róseas; estames 5-numerosos, distribuídos em um ou dois verticilos; filetes total ou parcialmente unidos em tubo, às vezes apresentando apêndices na região basal; conectivo às vezes alargado, principalmente em estames com duas a quatro tecas; anteras 1-4 tecas, dorsifixas ou basifixas, globosas, lineares, rimosas, extrorsas; ovário normalmente súpero, raramente semi-ínfero, raramente um ou quinze; óvulos 1-2-numerosos por lóculo; estilete indiviso, cilíndrico, filiforme; estigma capitado ou 5-lobado. Fruto cápsula, loculicida, valvar ou carnoso drupáceo, endocarpo geralmente com tricomas longos "paina", esbranquiçados, cremes a rufescentes ou, às vezes, polposo, indeiscente; sementes em número variado, glabras.

1. Ceiba glaziovii (Kuntze) K. Schum., Just. Bot. Jahresb. 26: 343.1900.

Xylon glaziovii Kuntze, Rev. Gen. Plant. 3 (2): 23. 1898. Figura 1.

Nome vulgar: Barriguda 
Chave para identificação das espécies.

1. Árvores com caule e ramos aculeados; flores com cinco estames 1. Ceiba glaziovii

1. Árvores com caule e ramos inermes; flores com mais de cinco estames 2

2. Estames totalmente unidos em um tubo; anteras sésseis; ovário semi-ínfero.......7. Quararibea turbinata

2. Estames parcialmente unidos em um tubo; anteras não sésseis; ovário súpero ...

3. Eriotheca crenulaticalyx

3. Tubo estaminal dividindo-se em filetes livres 3

3. Tubo estaminal dividindo-se em feixes de estames

4. Feixes de estames em dois verticilos; estames purpúreos no terço apical 4. Pachira aquatica

4. Feixes de estames em um verticilo; estames inteiramente brancos

5. Cálice verde; ovário com indumento seríceo

2. Bombacopsis retusa

5. Cálice marrom; ovário glabro a puberulento 6

6. Tubo estaminal dividindo-se em dez feixes; tubo estaminal e ovário glabros 6. Pseudobombax simplicifolium

6. Tubo estaminal dividindo-se em cinco feixes; tubo estaminal e ovário indumentados. 5. Pseudobombax marginatum

Árvore 6-15 m alt., copa ampla, bastante ramificada; tronco intumescido ca. $1 \mathrm{~m}$ diâm., aculeado, aculéos cônicos, ritidoma cinza-claro. Folhas compostas, digitadas, 4-7 folíolos; pecíolo 6-9,3 cm compr., cilíndrico, glabro, ligeiramente dilatado nas extremidades; peciólulo 2-4 mm compr., glabro; folíolos 4,5-13,5 x 3-6,3 $\mathrm{cm}$, elíptico-lanceolados, membranáceos a cartáceos, base aguda, ápice agudo-acuminado, margem levemente serreada principalmente na metade apical, ambas faces glabras. Inflorescências em cimeiras, fasciculadas, com até três flores ou às vezes flores solitárias; botões florais obovais a elípticos; flores $6,5-7,8 \mathrm{~cm}$ compr., brancas; pedicelo $0,7-1,1 \mathrm{~cm}$ compr., cilíndrico, rosado no botão, glabro; bractéolas 3-4 mm compr., ápice arredondado; receptáculo 2-4 mm compr., glabro, sem glândulas; cálice 2-2,5 cm compr., ápice com 3-5 laciniado, 5-10 mm compr., verde, externamente glabro, internamente glabro na base e seríceo no ápice; pétalas 5,4$7,2 \times 1,5-3 \mathrm{~cm}$, brancas, com estrias longitudinais púrpuras a magentas na base, obovadas, ápice ligeiramente emarginado, externamente vilosas, internamente glabras na base, velutinas em direção ao ápice; estames 5, parcialmente unidos, 3,9-6,5 cm compr.; tubo estaminal 1,5$3 \mathrm{~cm}$ compr., glabro, circundado na base por cin- co apêndices recobertos por tricomas ásperos; anteras brancas, sinuosas; ovário subcônico, glabro. Cápsula loculicida, 8-11,8 x 5,2-8,5 cm, piriforme, coriácea, glabra; sementes 6-7 x 4-6 $\mathrm{mm}$, marrom-escuras.

Material examinado: BRASIL. PERNAMBUCO: Alagoinha, 16/IX/1991 (fl.), A. Bocage 198 (IPA, PEUFR); Araripina, 29.VII.93 (fr.), A. Bocage 257 (IPA); Arcoverde, 16/VII/1955 (fl.), Andrade-Lima 2093 (IPA); Sítio Caixa d'água, margem da estrada Arcoverde/Pedra, 15/IX/1993 (fl.), A. Bocage 269 (IPA, PEUFR); Bom Jardim: 28/XII/1972 (fl.), Andrade-Lima 7153 (IPA); Brejinho, 17/IX/1991 (fl.), A. Bocage 203 (IPA, PEUFR); Brejo da Madre de Deus, 22/X/ 1991 (fl.) A. Bocage 236 (IPA, PEUFR); Caruaru, Estação Experimental do IPA, 19/IX/1991 (fl.), A. Bocage 226 (IPA, PEUFR); Custódia, Barro Vermelho, 11/VII/1990 (fl.), A. Bocage 14 (IPA, PEUFR); Flores, serra da Baixa Verde, 30/VII/1993 (fl.), A. Bocage 260 (IPA,PEUFR); Garanhuns, 11/1929 (fl.),. B. Pickel 2166 (IPA); Itaíba, 17/XI/1993 (f.). A. Bocage 275 (IPA,PEUFR); Jataúba, Sítio Salobro, 21/X/1991 (fl.), A. Bocage 233 (IPA, PEUFR); Pedra, 18/ IX/1991 (fl.), A. Bocage 222 (IPA, PEUFR); Poção, 21/X/1991 (fl), A. Bocage 232 (IPA, PEUFR); Recife: granja de Dois Irmãos, culti- 


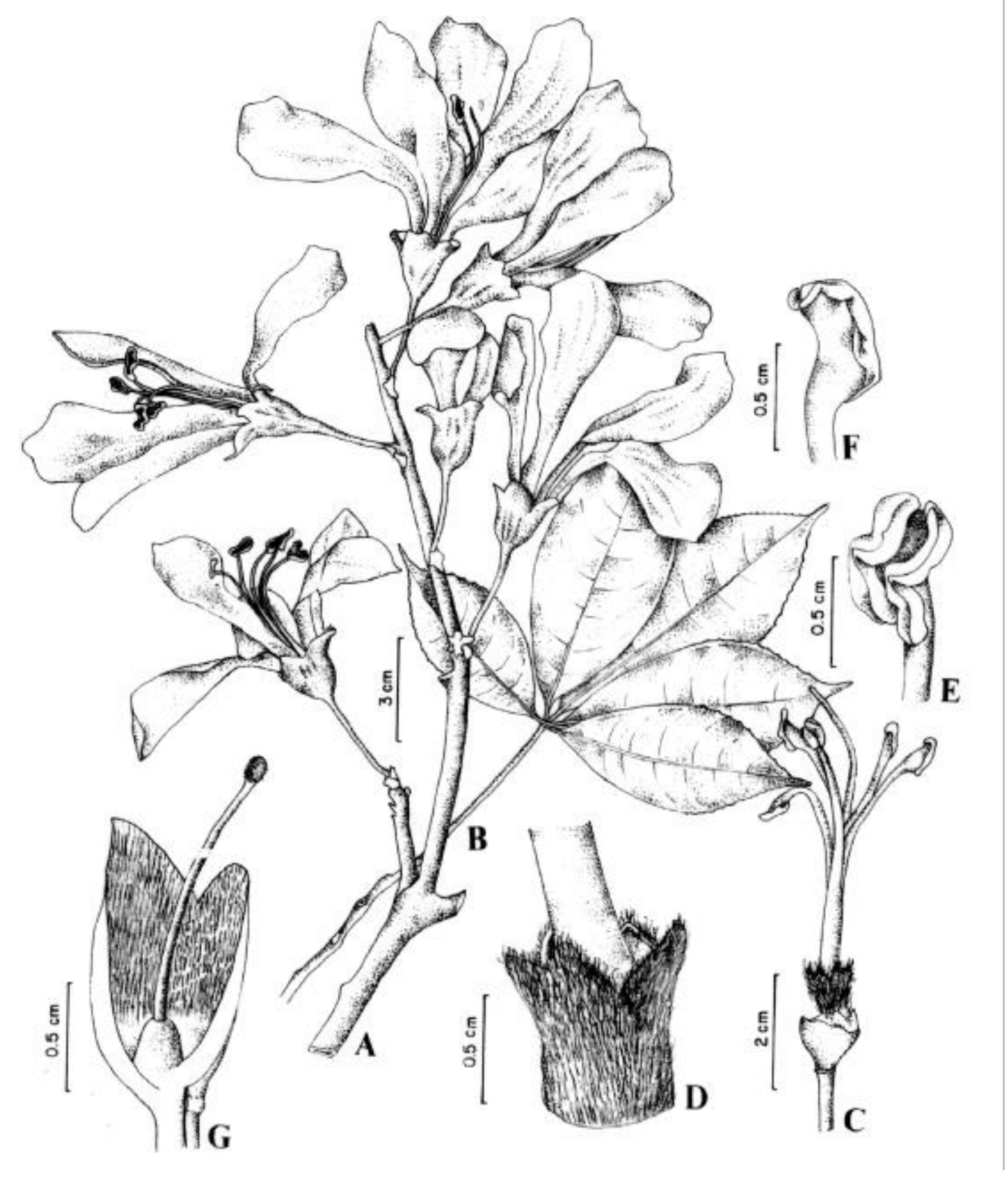

Figura 1. Ceiba glaziovii (Kuntze) K. Schum. (A-B : V. C. Lima 842); (C-G:A. Bocage 261) A: ramo com flores; B: folha; C: tubo estaminal; D: detalhe dos apêndices estaminodiais; E: antera em vista ventral; F: antera em vista dorsal; G: cálice em corte longitudinal mostrando o ovário. 
vada, 22/IX/1949 (fl.), Andrade-Lima 308 (IPA); Riacho das Almas, 19/IX/1991 (fl.), A. Bocage 231 (IPA, PEUFR); São José do Belmonte, 30/ VII/1993 (fl.) A. Bocage 259 (IPA, PEUFR); São José do Egito, estrada para Tuparetama, 17/IX/ 1991 (fl.), A. Bocage 207 (IPA, PEUFR); Serrita, 7 Km de Ipueira, 28/VII/1993 (fl.) A. Bocage 258 (IPA,PEUFR); Serra Talhada, Estação Experimental do IPA, 27/VII/1993 (fl.) A. Bocage 254 (IPA, PEUFR); Sertânia, 18/IX/1991 (fl.., fr.), A. Bocage 218 (IPA, PEUFR); Tacaratu, 13/IX/1990 (fl.), R. Pereira 567 et A. Bocage 187 (IPA, PEUFR); Triunfo, 11/VII/1990 (fl.), A. Bocage 21 (IPA, PEUFR); 17/IX/1991(fl., fr.), A. Bocage 212 (IPA, PEUFR); Venturosa, 18/ IX/1991 (fl.), A. Bocage 223 (IPA, PEUFR). Ceiba glaziovii apresenta distribuição restrita ao nordeste do Brasil, tendo sido encontrada nos Estados do Ceará, Paraíba, Pernambuco e Bahia. Em Pernambuco ocorre na caatinga ou sobre serras, na vegetação de transição entre caatinga e floresta montana. Constituem boas características diagnósticas para Ceiba glaziovii, o tronco com intumescência, os ramos e tronco aculeados, pétalas externamente vilosas, a presença de cinco estames e cinco apêndices no tubo estaminal. Ceiba glaziovii é bem próxima de $C$. erianthos K. Schum. e de C. pubiflora A. St.Hil., distinguindo-se da primeira pela presença de cinco apêndices bem evidentes no tubo estaminal, e da segunda por esta apresentar flores de coloração rósea e dez apêndices. Floresce de julho a outubro e frutifica de setembro a novembro.

2. Bombacopsis retusa (Mart. \& Zucc.) A. Robyns, Bull. Jard. Bot. Brux. 33 (1): 205.1963.

Bombax retusum Mart. \& Zucc., Flora 8 (1): 28. 1825. Figura 2.

Árvore 4 - 12 m alt., copa ampla; tronco 30-40 $\mathrm{cm}$ diâm.; ritidoma cinza com estrias longitudinais cinza escuro. Folhas compostas, digitadas, 3-4(-5) folíolos sésseis a subsésseis, agrupados nas extremidades dos ramos; pecíolo 1,3-
3,5 cm compr., cilíndrico, alargado nas extremidades, puberulento, tricomas ferrugíneos, às vezes com cerosidade esbranquiçada no ápice; folíolos 4,7-8,5 x 3,4-4,7 cm, obovais, obcordados, subcoriáceos, base aguda, ápice retuso, margem inteira, face adaxial glabra, face abaxial puberulenta, tricomas castanhos, principalmente nas nervuras principal e secundárias. Botões oblongo-lineares, levemente curvados; flores $14-17 \mathrm{~cm}$ compr., solitárias, axilares, nas extremidades dos ramos; pedicelo 1,4-1,7 cm compr., cilíndrico, glabro a puberulento; receptáculo 3-4 mm compr., com cinco glândulas externas, enegrecidas; cálice 1-1,7 cm compr., campanulado, verde, ápice truncado, 5-lobado a 5-apiculado, externamente glabro, internamente seríceo; pétalas 9-15,2 x 0,8-1,3 cm, lineares a lanceoladas, branco-esverdeadas, margem levemente onduladas, puberulentas em ambas as faces; estames 7-13,5 cm compr., brancos; tubo estaminal 2,5-5,7 cm compr., cilíndrico, dividindo-se em 10 falanges, glabro; parte livre 3,5$7,5 \mathrm{~cm}$ compr.; anteras oblongas, laranjadas; ovário piriforme, 5-lobulado, seríceo. Cápsula 9-10,5 x 6,6-8,1 cm, subglobosa com ápice apiculado, externamente glabra a levemente puberulenta, com tricomas ferrugíneos mais densamente na união das valvas, com endocarpo seríceo; sementes 3-4-anguladas, 1,4-2,2 x 1,6$2,3 \mathrm{~cm}$, brancas.

Material examinado: BRASIL. PERNAMBUCO: Petrolina, 08/XI/1956 (fl., fr.), AndradeLima 2620 (IPA); ibidem (fl.), A. Bocage 277 (IPA, PEUFR); ibidem (fl.), A. Bocage 280 (IPA, PEUFR).

Espécie endêmica do Brasil, ocorrendo em Minas Gerais, em campos cerrados (Robyns 1963 b). Neste trabalho constatou-se sua distribuição na região nordeste, nos estados da Bahia e Pernambuco. Neste último estado foi encontrada apenas no município de Petrolina, na caatinga, especialmente em áreas com areias quartzosas, sendo primeira referência para Pernambuco. Na Bahia, esta espécie ocorre na Chapada 


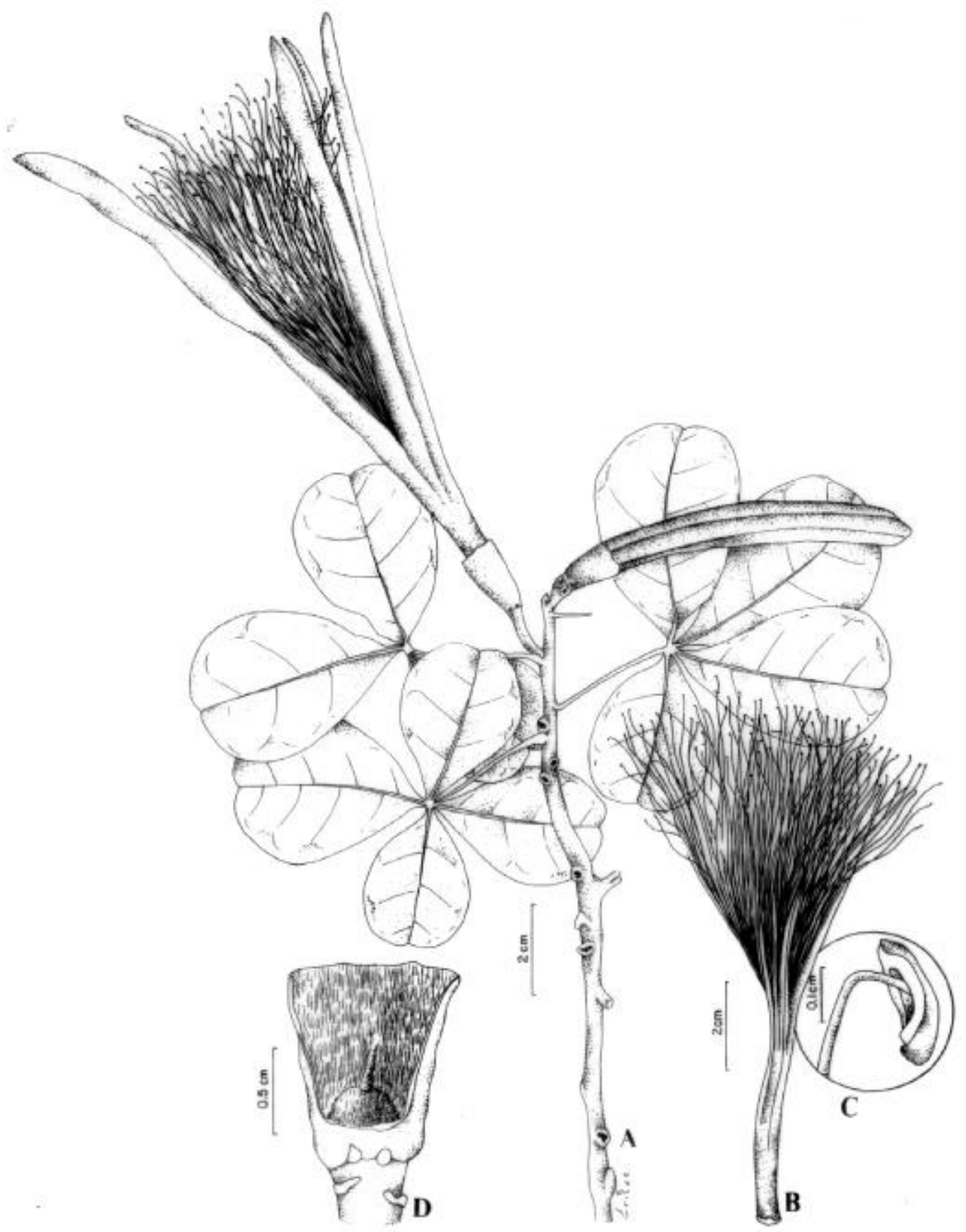

Figura 2: Bombacopsis retusa (Mart. \& Zucc.) A. Robyns (A-D : A. Bocage 273). A: ramo com flor; B: tubo estaminal; C: detalhe da antera; D: cálice em corte longitudinal mostrando o ovário. 
Diamantina, no Morro do Chapéu e em XiqueXique, na serra de Santo Inácio em afloramento areníticos. Bombacopsis retusa caracteriza-se pelas folhas aglomeradas nas extremidades dos ramos, com três a cinco folíolos de ápice retuso. Segundo Robyns (1963 b) é próxima de Bombacopsis paraense (Ducke) A. Robyns, diferindo desta pelo número de folíolos, pelo receptáculo com glândulas e pelo cálice e tubo estaminal glabros. Floresce de setembro a novembro e frutifica em novembro.

3. Eriotheca crenulaticalyx A. Robyns, Bull. Jard. Bot. Brux. 33 (1): 148. 1963. Figura 3. Nome vulgar: Munguba Árvore ca. $35 \mathrm{~m}$ de alt., tronco liso, com raízes tabulares. Folhas compostas digitadas, 3-5 folíolos; pecíolo 3-12,5 cm compr., cilíndrico, intumescido nas duas extremidades, puberulento a glabrescente; peciólulo 3-12 mm compr., glabro; folíolos 7,5-16 x 4-8,2 cm, oblongo-lanceolados a obovados, coriáceos, base decurrente e ápice retuso a levemente emarginado, margem inteira, suavemente revoluta, face adaxial glabra, face abaxial com indumento lepidoto. Inflorescências axilares, em cimeiras, com 2 a muitas flores; botões obovais, oboval-oblongos; flores 2,5-3,5 cm compr.; pedicelo 7-25 mm compr., delgado, cilíndrico, puberulento, tricomas escamosos; bractéolas triangulares, distribuídas espiraladamente ou verticiladamente, caducas; receptáculo 2-6 mm compr., alongado, sem glândulas, com tricomas escamosos; cálice 3-7 mm compr., cupuliforme, marromrufescente, ápice crenulado, externamente puberulento, com tricomas escamosos ferrugíneos, internamente seríceo; pétalas 2-2,5 x 0,9-1 $\mathrm{cm}$, obovadas, oblongo-lanceoladas, brancas, ápice unilateralmente apiculado, margem recurvada, vilosas em ambas as faces, exceto na base; estames 1,4-2 cm compr.; tubo estaminal 5-7 mm compr., cilíndrico, glabro; parte livre dos filetes 9-13 mm compr.; anteras dorsifixas, oblongas; ovário cônico, puberulento, tricomas escamosos ferrugíneos. Cápsula 5-7,3 x 3-6 cm, obovóide, com tricomas ferrugíneos quando jovem, glabrescente quando madura, valvas espessas; sementes 9-10 mm, piriformes, marrons, glabras, envolvidas por paina rufescente.

Material examinado: BRASIL: PERNAMBUCO: Cabo: Parque de Gurjaú, 5/XII/51 (fl.), A. Ducke et Andrade-Lima 65 (IPA); Goiana, 30/ XI/51 (fl.), A. Ducke et Andrade-Lima 57 (IPA); margem da estrada Tejucupapo-Ponta de Pedras, 21/XII/67 (fl.), O. C. Lira 160 (IPA); Jaboatão, 04/I/1925 (f.) B. Pickel 851 (SP); Recife: Curado, 03/II/1993 (f., fl., fr.), A. M. Miranda et al. s/n (PEUFR 13223); São Lourenço da Mata, 20/ X/27 (f., fl.),. B. Pickel 1478 (IPA).

Espécie com distribuição na América do sul, no Brasil, em Pernambuco (Robyns, 1963 b). Até o presente, só foi encontrada para este Estado, em mata de restinga e floresta atlântica, sendo uma espécie emergente, apresentando ca. de $35 \mathrm{~m} \mathrm{e}$ raízes tabulares, com até $2 \mathrm{~m}$ compr. Eriotheca crenulaticalyx é reconhecida pelo receptáculo sem glândula e pelo cálice com ápice crenulado. É próxima de Eriotheca, gracilipes (K. Schum.) A. Robyns, distinguindo-se por esta apresentar o receptáculo com glândulas e o cálice com ápice truncado, às vezes apiculado. Floresce de outubro a fevereiro e frutifica em fevereiro.

4. Pachira aquatica Aubl., Hist. Pl. Gui. Fr. 2: 726. 1775.Figura 4.

Nome vulgar: Carolina

Árvore 5-20 m alt.; tronco liso. Folhas compostas digitadas, com 5-7 folíolos; pecíolos 8$26 \mathrm{~cm}$ compr., cilíndrico, intumescidos nas extremidades, glabro, sulcado longitudinalmente; pecíolulo 5-30 mm compr.; estípulas triangulares, caducas; folíolos 8,5-31 x 5-10,5 cm, oblongo-lanceolados a ligeiramente obovados, subcoriáceos, base aguda, ápice acuminado a obtuso-apiculado, margem inteira a levemente sinuosa, às vezes revoluta, ambas faces glabras. Botões florais lineares, levemente curvados no ápi- 


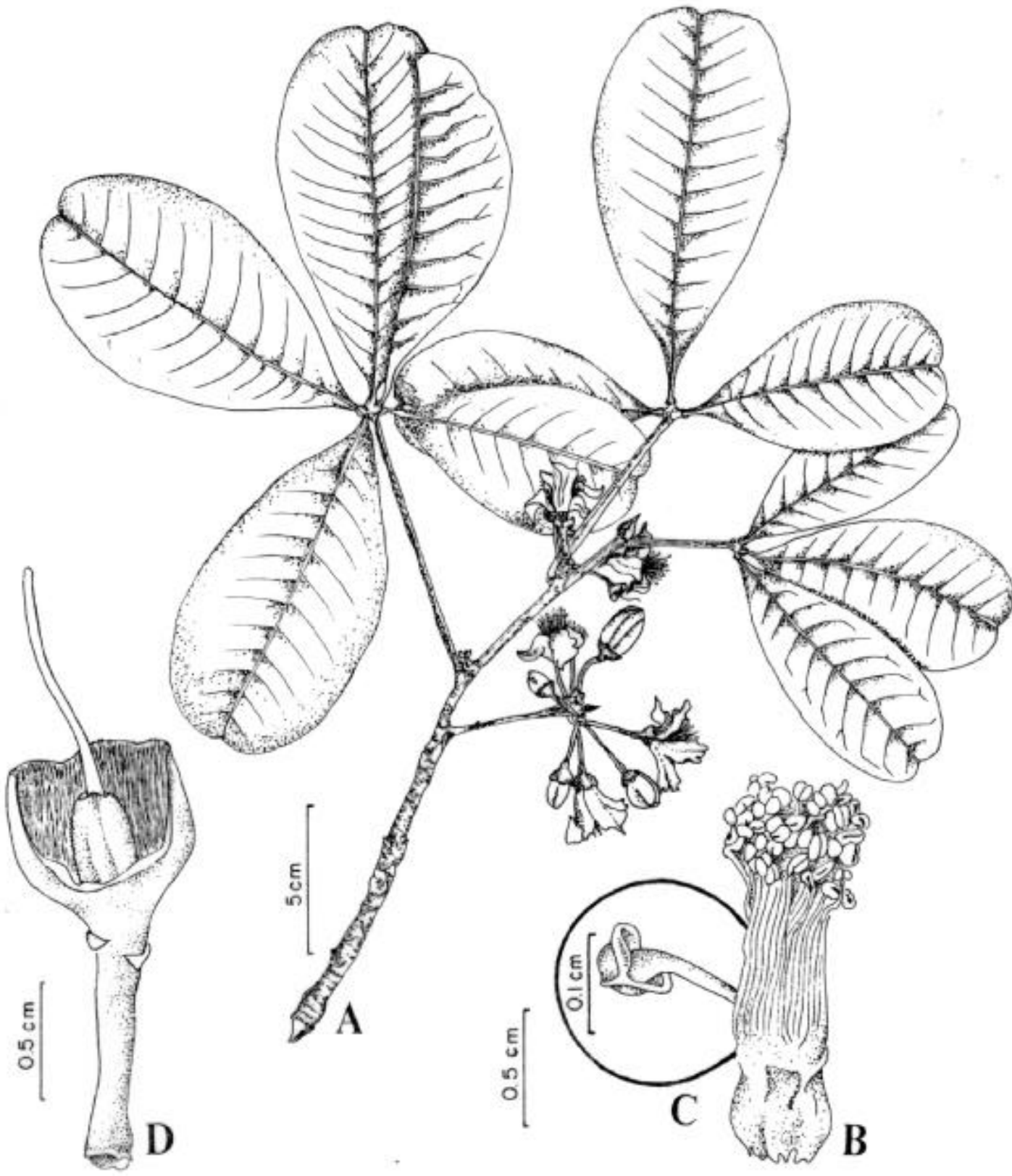

Figura 3. Eriotheca crenulaticalyx A. Robyns (A: O. C. Lira 160); (B-D : A. M. Miranda et al. s/n). A: ramo com flores; B: tubo estaminal; C: detalhe da antera; D: cálice em corte longitudinal mostrando o ovário. 
ce; flores 20-35 cm compr., solitárias, ou em cimeras com 2-3 flores, axilares, perfumadas; pedicelo 1,5-3,3 cm compr., cilíndrico, glabro ou com tricomas esparsos, ferrugíneos; bractéolas caducas; receptáculo3-4 mm compr., externamente com cinco glândulas avermelhadas; cálice 1,5-1,8 cm compr., campanulado, tubular, verde, ápice truncado, às vezes 5-apiculado, externamente puberulento, internamente seríceo; pétalas $25-31,5$ x 1,4-1,9 cm, linear-lanceoladas, branco-amareladas, ápice agudo, margem ondulada, externamente puberulentas, internamente pubescentes, enroladas após a antese; estames 20-25,5 cm compr., brancos, terço apical purpúreo; tubo estaminal 7,8-12,5 x 9-1,2 cm, dividindo-se em dois verticilos, verticilo externo com 5 feixes, dividindo-se em 10 feixes; verticilo interno com 5 feixes; anteras dorsifixas, lineares, avermelhadas; ovário piriforme, 5-costado, tomentoso; estilete $24-28,3 \mathrm{~cm}$ compr., branco, ápice purpúreo, tomentoso; estigma 5lobado, lobos filiformes, purpúreo. Cápsula loculicida, $11-22$ x 9,7-15 cm, subglobosa a oblongo-elíptica, indumento ferrugíneo, endocarpo seríceo; sementes 3-4 angulosas, 2,4-3,5 x 2,9 $4 \mathrm{~cm}$, brancas.

Material examinado: BRASIL. PERNAMBUCO: Amaraji, 30/III/1993 (fl.), A. Bocage 246 (IPA, PEUFR); Cabo, 24/X/1983 (fl.), A. Chiappeta s/n (IPA 45361); Olinda: VII/1914 (fl.), D. B. Pickel 329 (IPA, SP); Recife, 22/XI/1990 (fl.), J. L. H. Alves s/n (UFP 7842); 11/V/1993 (fl.), A. Bocage 251 (IPA, PEUFR); 25/V/1936 (fl.), V. Sobrinho s/n (IPA 155); cultivada, XI/ 1936 ( fl.), V. Sobrinho s/n (IPA 281); 02/XII/ 1952 (fl.), Andrade-Lima 1188 (IPA); 08/I/1962 (fl.), V. Sobrinho s/n (PEUFR 374 ); 14/V/1987 (fl.), D. Belo 58 (IPA); 21/II/1988 (fl.), L. C. Gomes 14 (PEUFR); s/d (fl.), M. C. Dornelas s/ n (UFP 5863); Petrolina, cultivada, XI/1985 (fl.), M. Ataíde et al. 662 (IPA); Primavera, 26/IV/ 1993 (fl.), A. Bocage 250 (IPA, PEUFR).

Paquira aquatica apresenta distribuição predominante na América Central e na América do
Sul. No Brasil ocorre no Amazonas, Pará e Maranhão, nas margens de rios e lagos, em ambientes muito úmidos Robyns (1963 b). A espécie é bastante cultivada em toda a América tropical, com fins ornamentais, sendo subespontânea em Pernambuco. É facilmente reconhecida pelas flores perfumadas com mais de $20 \mathrm{~cm}$, pelos estames brancos, púrpureos no ápice, pelos folíolos oblongo-lanceolados a ligeiramente obovados com ápice sempre acuminado a obtusoacuminado, pelo cálice campanulado e pelas pétalas de cor branco-amarelada. Tais características a diferencia de P. insignis (Sw.) Sav., cujos folíolos são obovados com ápice retuso a emarginado, o cálice é cupuliforme e as pétalas são de cor vermelho-enegrecida a escarlate. Floresce e frutifica durante quase todo ano.

5. Pseudobombax marginatum (A. St.-Hil.) A. Robyns, Bull. Jard. Bot. Brux. 33:73. 1963.

Pachira marginata A. St.-Hil., Fl. Bras. Mer., I (6): 260, tab. 51. 1827. Figura 5.

Nome vulgar: Embiratanha

Árvore 2,5-8 m alt., tronco de 30-40 cm diâm., ritidoma cinza, estrias longitudinais verdes. Folhas compostas, digitadas, 5 folíolos sésseis a sub-sésseis; pecíolo 4,5-12 cm compr., cilíndrico, intumescido nas extremidades, estriado longitudinalmente, glabro a pubescente; estípulas caducas; folíolos 4,5-17,5 x 2-5 cm, obovadoblongos, membranáceos a cartáceos, base decurrente, ápice arredondado acuminado, face adaxial glabra, face abaxial pubescente. Botões florais oblongo-lineares; flores solitárias, geminadas ou tríades, geralmente nas extremidades dos ramos 13-15 cm compr., brancas; pedicelo 1,5-4,3 cm compr., crasso, puberulento, tomentoso porção apical; bractéolas 3-4 x 6-7 mm, caducas; receptáculo 3-5 mm compr., densamente puberulento a tomentoso, com um a dois verticilos de glândulas; cálice 1,2-2 cm compr., campanulado, marrom-escuro, ápice truncado, levemente lobado-apiculado, externamente puberulento, internamente glabro na base, 


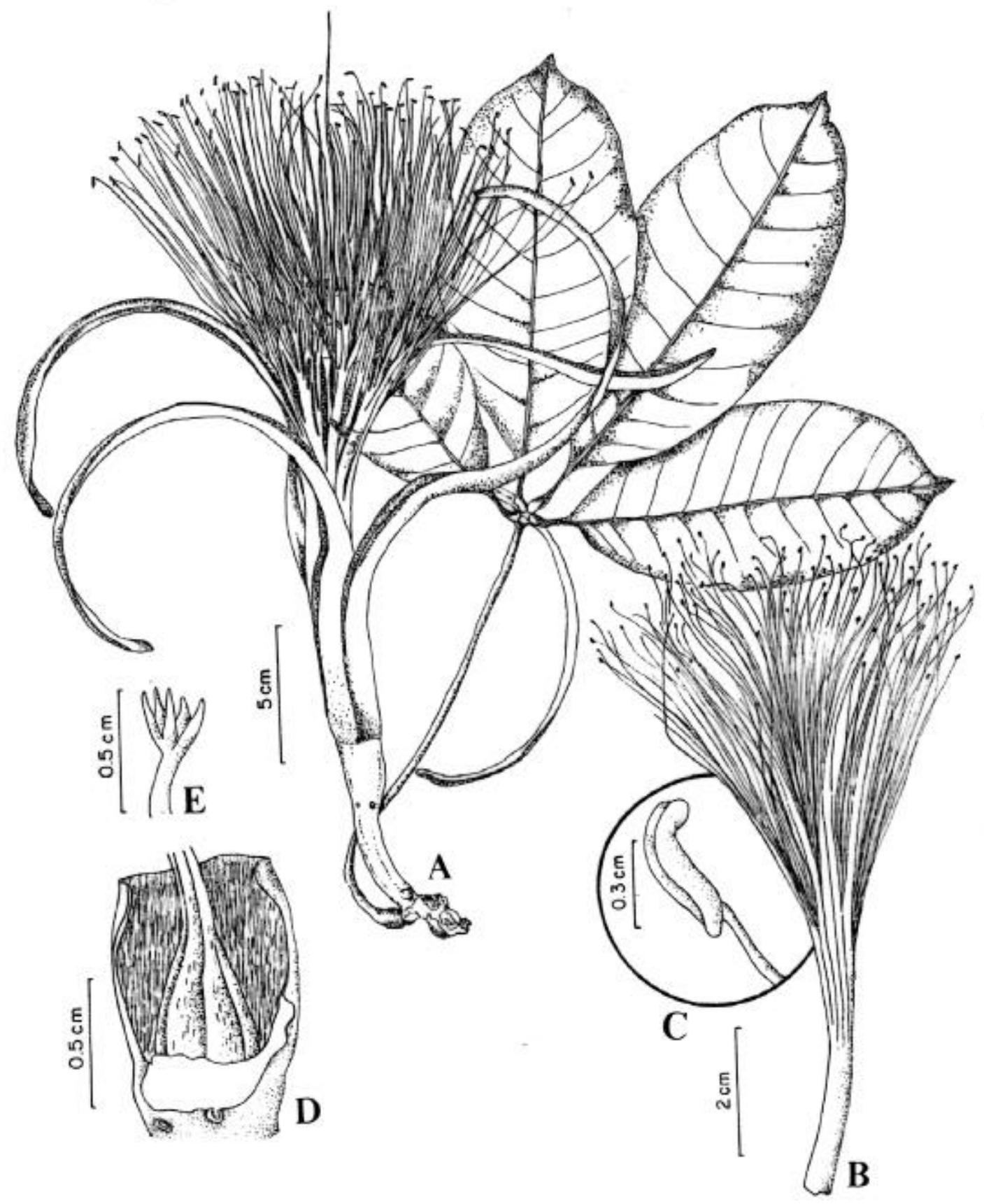

Figura 4. Pachira aquatica Aubl. (A-E : A. Bocage 251). A: ramo com flor; B: tubo estaminal; C: detalhe da antera; D: cálice em corte longitudinal mostrando o ovário; E: detalhe do estigma. 
seríceo ápice; pétalas 7-15,3 x 1,1-2,7 cm, lineares a oblongo-lineares, ápice obtuso, externamente verde-escuras, recoberta por tricomas em tufos, base glabra, internamente brancas, seríceas, recurvadas, caducas após antese; estames 6,5-13 cm compr., brancos; tubo estaminal 1-2 cm compr., dividindo-se em 5 feixes, totalmente viloso ou apenas no terço inferior; filetes 5,5$11 \mathrm{~cm}$ compr.; anteras basifixas, amareladas; ovário cônico, 5-anguloso, puberulento; estigma 5-lobado. Cápsula 10,5-16 x 4,8-6,5 cm, obovóide, 5-valvar, valvas 3-4 cm larg.; sementes 7-8 x 5-6 mm, arredondadas, marrom-escuras, testa brilhante, envolvidas por paina refescente.

Material examinado: BRASIL. PERNAMBUCO: Brejinho: 17/IX/1991 (fl.), A. Bocage 205 (IPA, PEUFR); Caruaru, na Estação Experimental do IPA de Caruaru, 16/IX/1993 (fl.), A. Bocage 270 (IPA, PEUFR); Floresta, 30/VI/1952 (fl., fr.), A. Lima et M. Magalhães 1157 (IPA); Ibimirim, 15/VII/1980 (fl., fr.), A. Lima et al. 06 (IPA); Itapetim, 15/IX/1993 (fl.), A. Bocage 267 (IPA, PEUFR); Ouricuri, 20Km da cidade de Ouricuri, 05/V/1971 (fl.), E. P. Heringer et al. 530 (IPA, PEUFR); Serra Talhada, Estação Experimental do IPA, 12/VII/1990 (fl.), A. Bocage 25 (IPA, PEUFR); Salgueiro, 11/V/1971 (fl.), E. P. Heringer et al. 700 (IPA, PEUFR); Serrita, 29/VII/1981 (fl., fr.), A. Lima et al. 100 (IPA, PEUFR); Sertânia, 18/IX/1991 (fr.), A. Bocage 216 (IPA, PEUFR); Tabira, 17/IX/1991 (fl., fr.), A. Bocage 199 (IPA, PEUFR); Triunfo, 14/IX/1993 (fl.), A. Bocage 264 (IPA, PEUFR); Venturosa, Parque Estadual de Pedra Furada, 01/ IX/1992 (fl.), V. C. Lima 837 (IPA, PEUFR).

Pseudobombax marginatum apresenta distribuição exclusiva na América do Sul, especialmente na Bolívia, Paraguai, Brasil e Peru. Neste último país, é encontrada em áreas com cerca de $1000 \mathrm{~m}$ de altitude (Robyns, 1963 b). No Brasil, ocorre nas regiões Sudeste (Minas Gerais) e Centro-Oeste (Goiás e Mato Grosso). Neste trabalho, constatou-se que Pseudobombax margi- natum possui uma distribuição mais ampla, alcançando o Nordeste nos Estados de Pernambuco, Ceará e Paraíba. Em Pernambuco ocorre exclusivamente na região semi-árida, na caatinga, sendo ocasionalmente encontrada em maiores altitudes, sobre serras, na vegetação de transição entre caatinga e floresta montana, sendo primeira referência para este Estado. Pseudobombax marginatum caracteriza-se por ser pouco ramificada, pelo tamanho das flores 13-15 $\mathrm{cm}$, estames totalmente brancos e cápsulas obovóides. Floresce de maio a setembro e frutifica de julho a setembro.

6. Pseudobombax simplicifolium A. Robyns, Bull. Jard. Bot. Brux. 33: 61.1963. Figura 6. Material examinado: BRASIL. PERNAMBUCO: Petrolina, 21/VI/1952 (fl.), Andrade-Lima et M. Magalhães 1055 (IPA); ibidem, 07/IX/73 (fr.), Andrade-Lima 7424 (IPA); ibidem, cerca de $6 \mathrm{Km}$ do posto da polícia federal, em direção à cidade, 28/VII/1993 (fl., fr.), A. Bocage 255 (IPA,PEUFR); ibidem, A. Bocage 256 (IPA,PEUFR); próximo ao CPATSA, 28/VIII/ 1993 (fl.), A. Bocage 274 (IPA,PEUFR).

Pseudobombax simplicifolium apresenta distribuição restrita à região Nordeste do Brasil, ocorrendo nos Estados da Bahia, Pernambuco e Piaui. Em Pernambuco, sua distribuição parece ser restrita ao extremo oeste do Estado, na zona de caatinga, em solos arenosos, onde aparecem grandes populações. Esta espécie pode ser facilmente reconhecida pelos ramos longos, com os inferiores descendentes, alcançando quase o chão, e os superiores ascendentes e pelas folhas simples. Segundo Robyns (1963 b), esta espécie é próxima de Pseudobombax campestre (Mart. et Zucc.) A. Robyns diferindo, especialmente, pelas suas folhas simples, agrupadas nos ramos curtos, enquanto que em Ps. campreste estas são compostas e reunidas nas extremidades dos ramos. Pseudobombax simplicifolium floresce de junho a agosto e frutifica de julho a agosto. Sua casca pode ser utilizada na produ- 


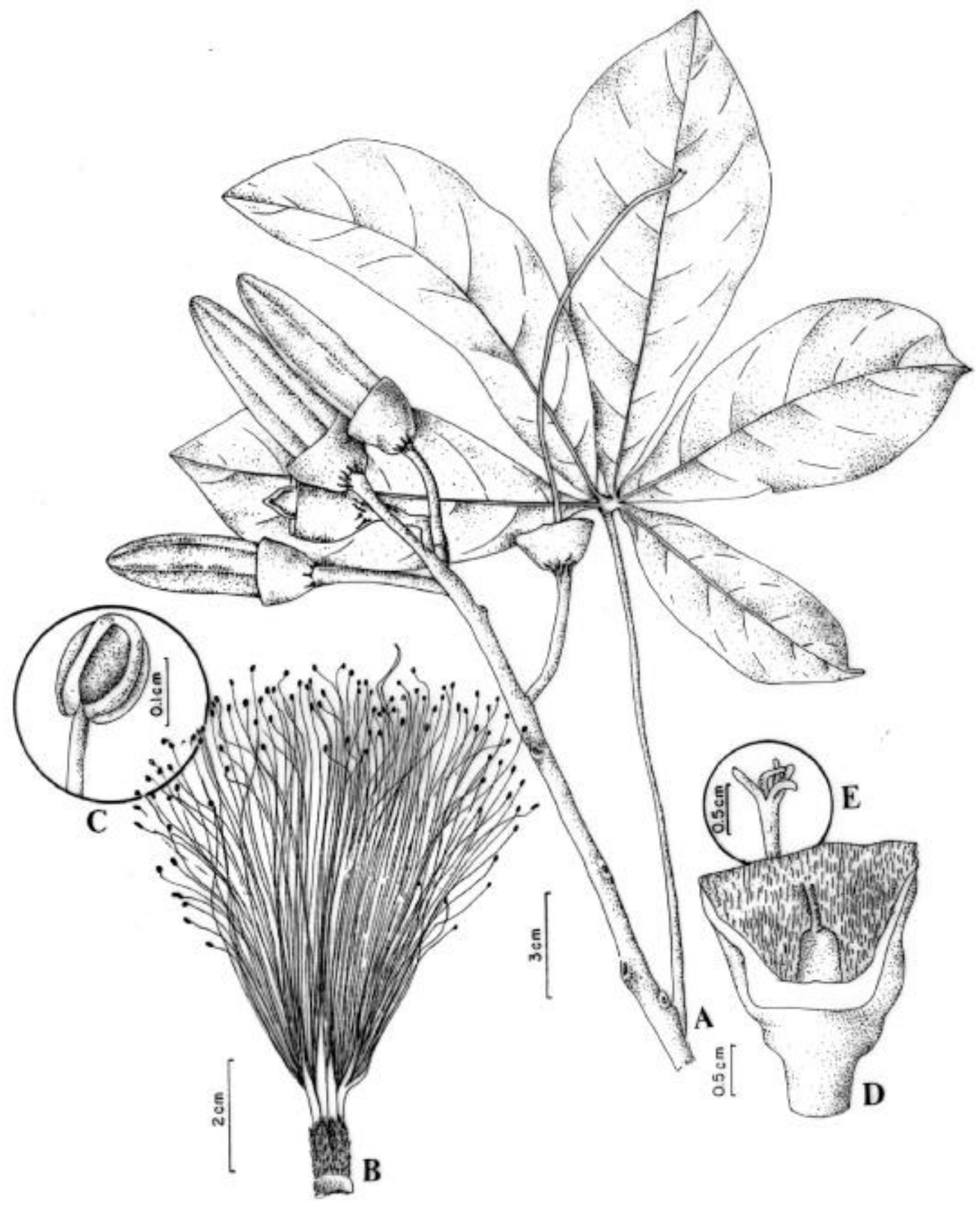

Figura 5. Pseudobombax marginatum (A. St.-Hil.) A. Robyns (A : E. P. Heringer et al. 530); (B-E : A. Bocage 265) A: ramo com botões; B: tubo estaminal; C: detalhe da antera; D: cálice em corte longitudinal mostrando o ovário; E: detalhe do estigma. 


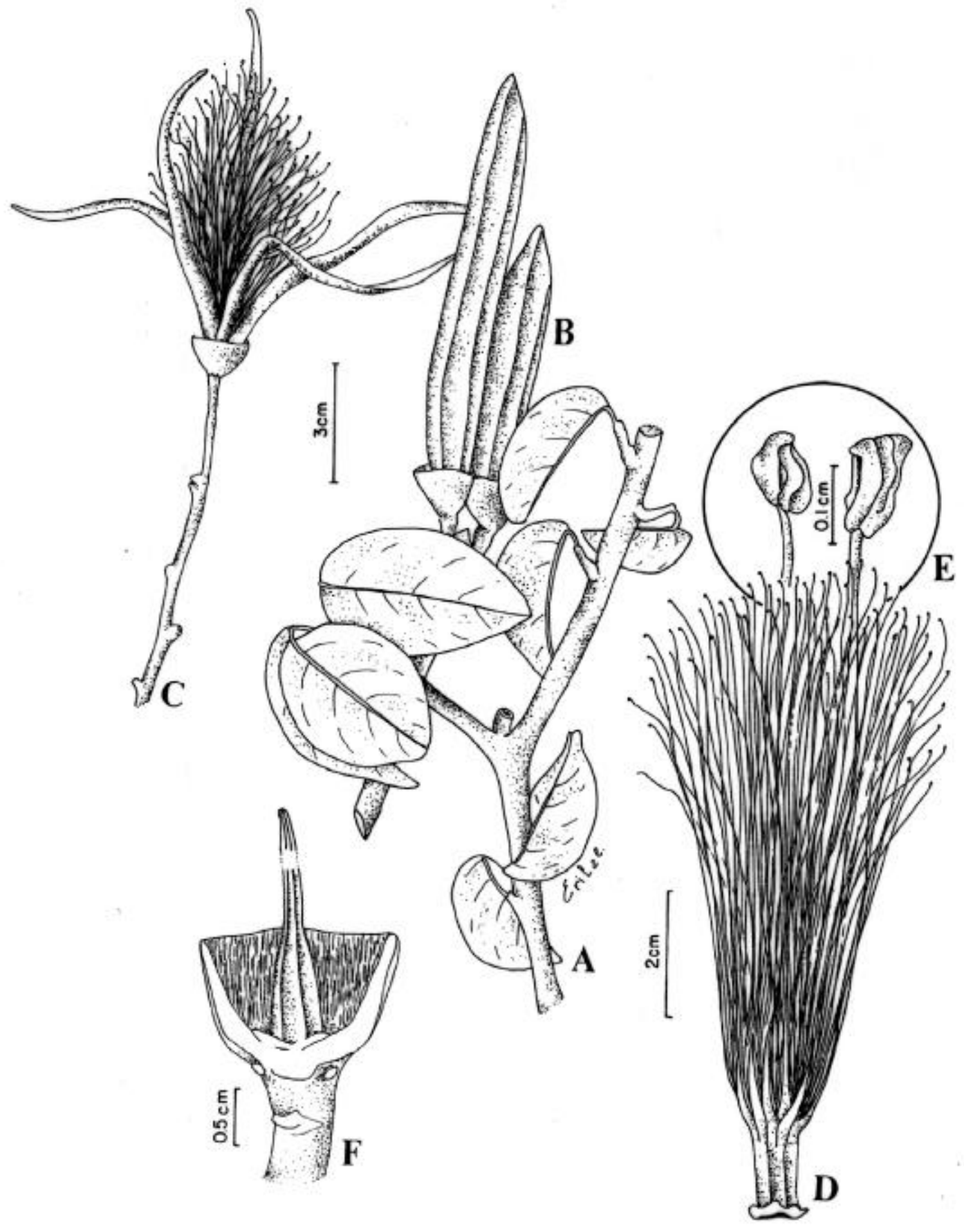

Figura 6. Pseudobombax simplicifolium A. Robyns (A, B, D, E e F : A. Bocage 258); (C : A. Bocage 255) A: ramo; B: botões florais; C: Flor; D: tubo estaminal; E : detalhes da antera; F: cálice em corte longitudinal mostrando o ovário. 
ção de estopa, para calafetar embarcações e que a paina, proveniente dos fruto, é usada como enchimento de travesseiros (Andrade-Lima, 1989).

7. Quararibea turbinata (Sw.) Poir., Encyc. Suppl. 4: 636. 1816.

Myrodia turbinata Sw., Prod. Veg. Ind. Occ. 102. 1788.Figura 7.

Árvore 3-10 m alt.; tronco liso; ramos verticilados; folhas simples, pecíolo 4-11 mm compr., recoberto por tricomas estrelados; estípulas triangulares, caducas; lâmina 5,1-22,5 x 2,5-9,1 cm, lanceolada, obovado-oblonga a obovada, membranácea, base obtusa, ápice acuminado, margem inteira a levemente sinuosa; ambas faces puberulentas, tricomas estrelados. Botões florais obovais, tricomas estrelados; flores 2,9-3,8 cm compr., axilares; pedicelo 6-13 mm compr., tricomas estrelados; bractéolas 1-2 mm compr., triangulares, tricomas estrelado; receptáculo $2 \mathrm{~mm}$ de compr., tricomas estrelados; cálice 1,5-1,9 cm compr., turbinado, tubular, verde, ápice 3-5 lacínios irregularmente partidos; lacínios 1-4 mm compr., externamente, tricomas estrelados, internamente seríceo; pétalas 1,4-3 x 7-10 mm, linear-espatuladas, reflexas, brancas, base amarelada, ápice agudo, tricomas estrelados em ambas as faces; estames totalmente unidos, 22,4 cm compr,, 5-lobado, pubescente; anteras, sésseis, dispostas aos pares no ápice do tubo estaminal, brancas; ovário semi-ínfero, bilocular, dois óvulos por lóculo; estigma 5-lobado, discóide, creme. Drupa, 1,7-2,1 x 1,9-2,7 $\mathrm{cm}$, globoso a levemente trilobado, apiculado, alaranjado quando maduro, glabro, mesocarpo fibroso, com cálice persistente; semente única ca. $1 \mathrm{~cm}$ compr., ovóide, glabra.

Material examinado: BRASIL. PERNAMBUCO: Escada, Engenho Conceição, s/d (fl.), O. C. Lira 242 (IPA); Paudalho, Usina Mussurepe, 20/ XI/1951 (fl., fr.), A. Lima 27 (IPA, PEUFR); Recife, Curado, 27/IV/1993 (fl.), A. Bocage 249 (IPA,
PEUFR); ibidem, 23/VIII/1993 (fr.), A. Bocage 273 (IPA, PEUFR); ibidem, 05/II/1987 (fl.), S. I. Silva s/n (UFP 4602).

Quararibea turbinata está distribuída na América do sul, tendo sido registrada no Suriname (Lemée, 1952) e Brasil, nos estados de Pernambuco, Rio de Janeiro e Minas Gerais (Santos, 1969), habitando preferencialmente, florestas úmidas próximas ao litoral. Em Pernambuco poucos indivíduos foram encontrados em remanescentes de Floresta Atlântica. A espécie caracteriza-se pelos ramos verticilados com folhas simples, pelas flores brancas, pendentes, pelo tubo estaminal totalmente unido com anteras sésseis, como também pelos frutos de cor laranja. Floresce de fevereiro a abril, embora indivíduos floridos tenham sido registrados, em novembro, e frutifica agosto e novembro

\section{Agradecimentos}

As autoras agradecem aos curadores dos herbários citados, pelo empréstimo e envio do material estudado; ao Dr. João Semir, da UNICAMP, pelas valiosas sugestões e ao $\mathrm{CNPq}$, pela bolsa concedida à primeira autora.

\section{Referências Bibliográficas}

Adams, C. D. 1972. Flowering Plants of Jamaica. Mona: University of the West Indies, p. 478- 479.

Andrade-Lima, D. de A.1989. Plantas das caatingas. Rio de Janeiro: Academia Brasileira de Ciência, $243 \mathrm{p}$.

Bakhuizen van den Brink, R. C. 1924. Revisio Bombacacearum. Bulletin do Jardin Botanique de Buitenzorg, Java, Série 3, 6 (2):160-240.

Barbosa, M. C. A. \& Barbosa, M. R. V. 1996. Pp. 145150. Os Herbários do Nordeste. In: E. V. S. B. Sampaio; S. J. Mayo \& M. R. de V. Barbosa (Eds.), Pesquisa Botânica Nordestina: progresso e perspectivas, $\mathrm{SBB}$, Recife.

Barroso, G. M.; Guimarães, E. F.; Ichaco, C. L. F.; Costa, C. G. \& Peixoto, A. L. 1978. Sistemática de Angiosperma do Brasil. São Paulo: Universidade de São Paulo, 255p. 


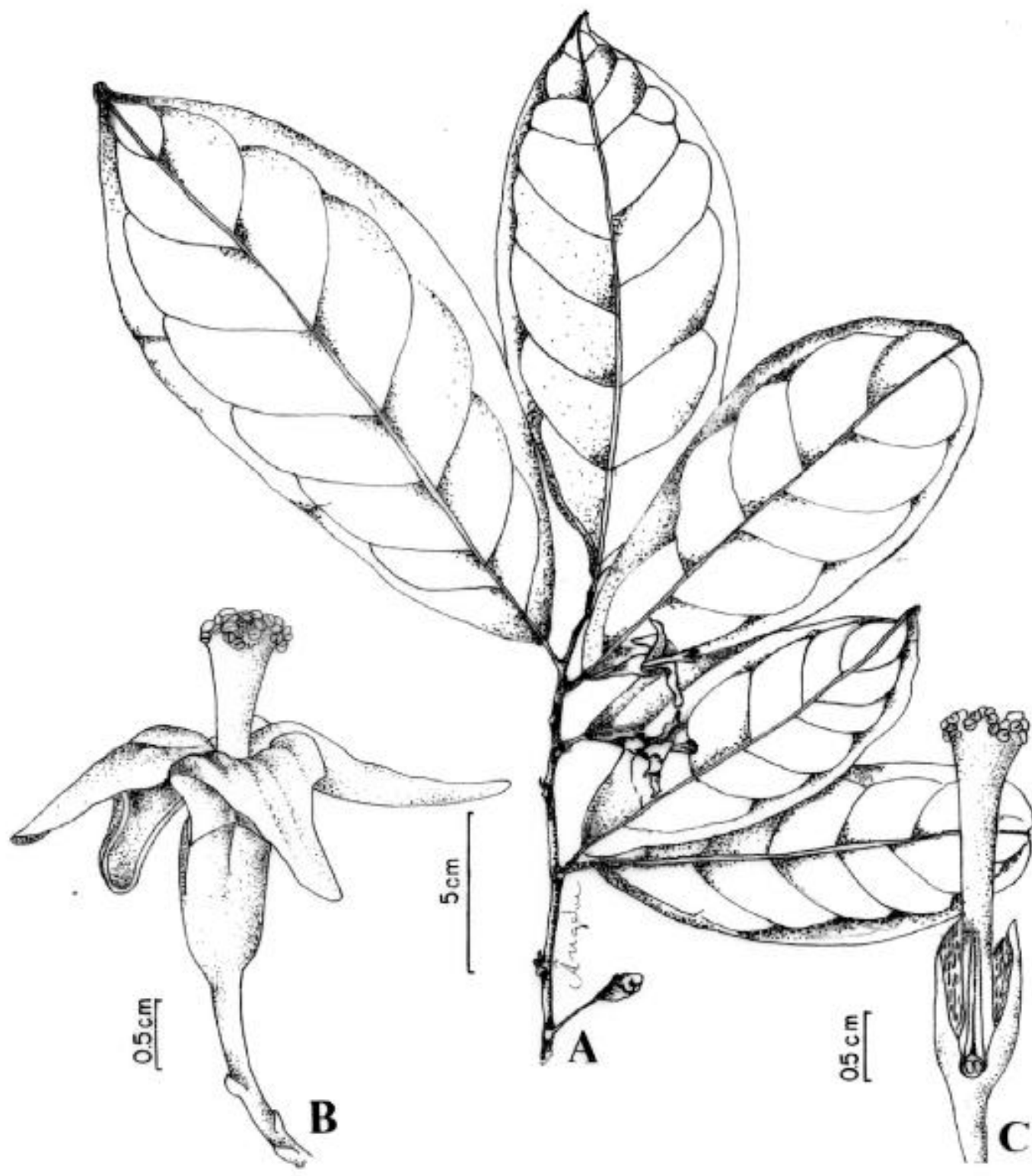

Figura 7. Quararibea turbinata (Sw.) Poir. (A-C : A. Bocage 249). A: ramo com flores; B: flor; C: corte longitudinal da flor mostrando a face interna do cálice, ovário e tubo estaminal. 
Bentham, G. 1862a. Notes on Malvaceae and Sterculiaceae. Journal Proceedings of the Linnean Society; Botany, London, 6: 97-123.

Bentham, G. Malvaceae. In: G. Bentham \& J. D. Hooker (Eds.), 1862 b. Genera plantarum. London: Reeve \& Co. et Williams \& Norgate, l (1): 195-213.

Croizat, L. 1964. La distribution des Bombacées: mise au point biogeographique. Adansonia, [S.1], 4 (3): 427-455.

Cronquist, A. 1981. An integrated system of classification of flowering plants. New York: Columbia University Press, $1262 \mathrm{p}$.

De Candolle, A. P. 1824. Bombaceae. Prodromus systematis naturalis regni vegetabilis. Paris: Victoris Masson et Filii, 5: 475-480.

Ducke, A. 1925. Plantes nouvelles ou peu connues de la région amazonienne. Arquivos do Jardim Botânico do Rio de Janeiro, Rio de Janeiro, 4:1-29.

Ducke, A. 1930. Plantes nouvelles ou peu connues de la region Amazonienne. Arquivos do Jardim Botânico do Rio de Janeiro, Rio de Janeiro, 5:101-187.

Dugand, A. 1969. Flora de Colombia y países vecinos, III. Caldasia, Colômbia, 10 (48): 247-286.

Esteves, G. L. 1992. Flora da Serra do Cipó, Minas Gerais, Bombacaceae. Boletim de Botânica da Universidade de São Paulo, São Paulo, 3:161-164.

Esteves, G. L. 1996. Bombacaceae. In: M. M. F. de Melo et al. (Eds.), Flora Fanerogâmica da Ilha do Cardoso. Cananéia, São Paulo, 4: 85-89.

Fuchs, H. P. 1967. Pollen morphology of the family Bombacaceae. Review of Palaeobotany and Palynology, Amsterdam, 3:119-132.

Gibbs, P. E.; Semir, J. \& Cruz, N. D. da. 1988. A proposal to unite genera Chorisia Kunth. and Ceiba Miller. (Bombacaceae). Notes from the Royal Botanic Garden Edinburg, Edinburgh, 45 (1): 125-136

Gooding, E. G. P. ; Loveless, A. R. \& Proctor, G. R. 1965. Flora of Barbados. London: Henry Blacklook, 486 p.

Heel, W. A. van. 1966. Morphology of the androecium in Malvales. Blumea, Leyden, 13 (2): 254-295.

Holmgren, P. K.; Holmgren, N. H. \& Barnet, L. C. 1990. Index Herbariorum, Part 1: The herbaria of the world. 8 ed. New York Botanical Garden, New York.

Hutchinson, J. 1967. The Genera of Flowering Plants; Dicotyledones. Oxford: Clarendon Press, 2:659.

Lemee, A. M. V. 1952. Bombacacées. Flore de la Guyane Françoise. Paris, Brest, 2: 371-374.
Macbride, J. 1956. Flora of Peru. Field of Museum Natural History, Botanical Series, Chicago, 13 (2): 601-605.

Martins, V. L. C. 1993. Espécies brasileiras de Eriotheca Schott \& Endlicher (Bombacaceae). Rio de Janeiro: Universidade Federal do Rio de Janeiro, viii+ 200p. Tese de Mestrado.

Metcalfe, C. R. \& Chalk, L. 1950. Anatomy of the dicotyledons. Oxford: Clarendon Press, 2: 1500.

Moscoso, R. M. 1943. Florae Dominguensis (Catalogo de la Flora Dominicana); Spermatophyta. New York: 732 p.

Nilsson, S. \& Robyns, A. 1986. Bombacaceae Kunth. World Pollen and Spore Flora. [S.1.] 14: 1-59.

Paula, J. E. de. 1969. Estudo sobre Bombacaceae.I. Contribuição para o conhecimento dos gêneros Catostemma Benth. Scleronema Benth., da Amazônia Brasileira. Ciência e Cultura, São Paulo, 21 (4): 697-719.

Paula, J. E. de. 1976a. Estudos sobre Bombacaceae. IV . Anatomia de Catostemma albuquerquei Paula. Acta Amazônica, Manaus, 6 (4): 439-448.

Paula, J. E. de. 1976b. Estudos sobre Bombacaceae. V. Investigação anatômica das madeiras de Catostemma commune Sandwith, Catostemma sclerophyllum Ducke e Scleronema micranthum Ducke, com vistas à polpa, papel e taxônomia. Acta Amazônica, Manaus, 6 (2): 155-161.

Paula, J. E. de. 1980. Estudo anatômico das madeiras de Viola sebifera Aubl. e Pseudobombax tomentosum (Mart. \& Zucc.) A. Robyns visando o seu aproveitamento tecnológico. Brasil Florestal, Brasília, 10 (42): 35-52.

Ribeiro, J. E. L. da S. \& Esteves, G. L. 1999. Bombacaceae. Pp. 269-271. In: Ribeiro, J. E. L. da S. et al. Flora da Reserva Ducke; Guia de identificação das plantas vasculares de uma floresta de terra-firme na Amazônia Central. Instituto de Pesquisa da Amazônia, Manaus.

Robyns, A. 1963a. Bombacaceae. Flore du Congo du Ruanda et du Burundi ineac, Bruxelles, 10:191-204.

Robyns, A. 1963b. Essai de Monographie du genre Bombax L. s.l. (Bombacaceae). Bulletin du Jardin Botanique de l'État à Bruxelles, Bruxelles, 33 (1):1-315.

Robyns, A. 1964. Bombacaceae in Flora of Panamá. Annals of the Missouri Botanical Garden, St. Louis, 51: 37-68.

Santos, E. 1966. Bombacaceae do Estado da Guanabara. Rodriguesia, Rio de Janeiro, 25 (37): 41-49. 
Santos, E. 1967. Bombacaceae. Flora Ilustrada Catarinense, Itajaí, p. 1-39.

Santos, E. 1969. Bombacaceae. Flora Ecológica de Restinga do Sudeste do Brasil, Rio de Janeiro, p. 1-25.

Schumann, C. K. 1886. Bombacaceae. In: C. F. P. Martius; A. G. Eicher \& I. Urban (Eds.), Flora Brasiliensis. Monachii: Lipsitae, 12 (3): 201-250.

Schumann, C. K. 1895. Bombacaceae. In: A. Engler \& K. Prantl (Eds.), Die natürlichen Pflanzenfamilien. Leipig: Verlag von Wilhelm Engelmann, part. 4, div. 6, p. 53-68.

Sharma, B. 1970. Contribution of the Bombacaceae.

Proceedings of the Indian Academy of Sciences, Bangalore, 36b: 175-191.
Standley, P. C \& Steyermark, J. A.1949. Bombacaceae. Flora of Guatemala. Fieldiana, Chicago, 24 (6): 386-403.

Tsukada, M. 1964. Pollen morphology and identification modern and fossil tropical pollen with emphasis on Bombacaceae. Pollen et Spores, Montpellier, 61: 393-462.

Vischer, W. 1920. Sur les Quararibea Aubl. Un genre de Bombacées à ovaire infère. Bulletin de la Société Botanique de Genève. Genève, 11 (5/9):199-210.

Wild, H. \& Gonçalves, M. L. 1979. Bombacaceae. Pp. 1-11. In: E. J. Mendes (Ed.), Flora de Moçambique. Lisboa:Junta de Investigações Científicas do Ultramar. 